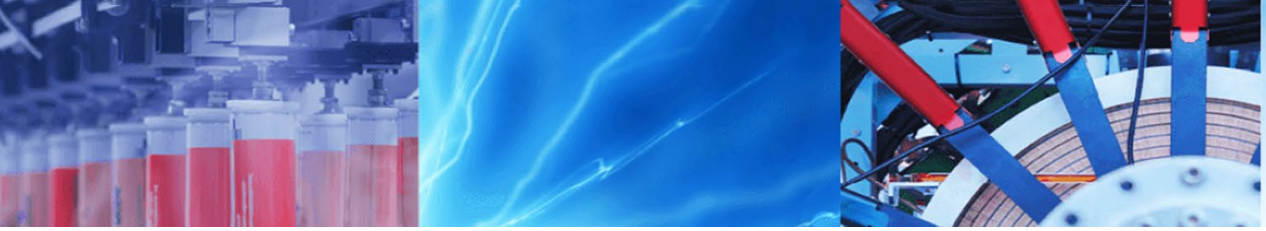

Research Article

\title{
Metal nanoparticle-carbon nanotubes hybrid catalysts immobilized in a polymeric membrane for the reduction of 4-nitrophenol
}

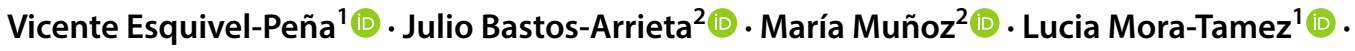 \\ Nadia M. Munguía-Acevedo ${ }^{1}$ (D) Ana Lilia Ocampo ${ }^{1}$ (i) - Josefina de Gyves ${ }^{1}$ (D)
}

(c) Springer Nature Switzerland AG 2019

\begin{abstract}
In this work, the synthesis of silver and copper nanoparticles and bimetallic silver-platinum and copper-platinum nanoparticles, in previously functionalized multi-walled carbon nanotubes (MWCNT), was carried out using the intermatrix synthesis for the charge of the first metal, and a galvanic replacement for the deposition of a second metal to form the bimetallic NPs. Well-controlled small size NPs were obtained as demonstrated by TEM, with a homogeneous distribution and mean particle diameters of ca. $2.9 \mathrm{~nm}$. The hybrid MNPs/MWCNTs catalysts were characterized by FTIR, TEM and XPS. The metal content was determined by TGA and validated via FAAS. Thereupon, the metal-MWCNTs hybrid catalysts were incorporated into a polymeric membrane (PM) and characterized by SEM. The effects of the hybrid catalyst-polymeric support interactions and the role of the MNPs/MWCNTs/PM materials as heterogeneous catalysts were evaluated from the catalytic performance on the reduction of 4-nitrophenol as a model reaction. An apparent rate constant normalized by the metal content of $1706.7 \mathrm{~s}^{-1} \mathrm{~mol}^{-1}$ was achieved for the best system (Ag-PtNPs/MWCNTs/PMR) along with a decrease in the percentage of conversion from $95 \%$ (first cycle) to $80 \%$ (third cycle). Results indicated that the catalytic activity depends mainly on the MNPs size and the metal content in the catalyst. The catalytic activity of the MNPs/MWCNTs was only 3 times higher than for the MNPs/MWCNTs/PMs catalysts, with the former presenting the advantage of being easily recovered from the reaction medium, thus, demonstrating the capability to perform an efficient and sustainable process.
\end{abstract}

Keywords Multi-walled carbon nanotubes · Mono and bimetallic nanoparticles · Polymeric membranes · Hybrid catalyst · Heterogeneous catalysis · 4-Nitrophenol reduction

\section{Introduction}

The unique properties that metal and metal oxide nanoparticles (MNPs, MONPs) exhibit regarding chemical reactivity and magnetic activity combined with the specific properties of carbon materials have led to enormous attention towards these hybrid materials and contributed to them arousing interest in many applications, particularly in energy storage, electronics and heterogeneous catalysis [1]. Aggregation into larger particles or particle arrays is known to be one of the most common features of MNPs leading to a loss of catalytic activity and stability. Therefore, protective ligands, surfactants and polymers are frequently used as stabilizers or supports to avoid aggregation.

In catalysis, clear examples of polymers [2] used as supports are carbon materials as well as diverse carbon nanostructures such as nanocoils [3, 4], nanofibers [3,5] and nanotubes $[3,6-8]$. Some of their main advantages are as follows: their chemical, mechanical and thermal resistance; the possibility of controlling their porosity and surface chemistry to a certain degree; and their electronic

$\triangle$ Josefina de Gyves, degyves@unam.mx | 'Departamento de Química Analítica, Facultad de Química, Universidad Nacional Autónoma de México, 04510 Ciudad de México, México. ${ }^{2}$ Department of Chemistry, Universitat Autònoma de Barcelona, 08193 Cerdanyola del Vallés, Barcelona, Spain.

SN Applied Sciences (2019) 1:347 | https://doi.org/10.1007/s42452-019-0357-z 
properties. Particularly, for the study of liquid-phase reactions, multi-walled carbon nanotubes (MWCNTs) are the most promising due to their high external surface area and mesoporosity [1]. Furthermore, it has been demonstrated that the catalytic process improves as the size of the catalyst decreases, with the optimum surface areas being those obtained with particle sizes between 1 and $10 \mathrm{~nm}$. Independent of the various methods that have been reported for MNP production, the most widely used metals in catalysis are noble metals, and although the amount of metal used in a catalytic reaction has diminished, the high costs still represent a major limitation for industrial applications. Nowadays, interesting advantages are reported to be obtained with the development of bimetallic NPs, where the use of less expensive metals, such as copper, titanium, iron, nickel and cobalt [9-13], allow the enhancement of the electrocatalytic activity as well as several other reactivities (optical, electronic, magnetic).

Concerning the preparation of MNP/carbon nanotube (CNT)-supported catalysts, several methods such as incipient wetness impregnation, ion-exchange, organometallic grafting, electron beam evaporation and deposition/ precipitation have been used [14-16]. To increase the potential applications of CNTs, several strategies have been implemented such as pretreatment procedures to achieve optimal interaction between the support and the catalyst precursor as well as their incorporation into polymeric membranes with or without pretreatment. In this manner, with regards to the first approach, oxidative treatments with $\mathrm{HNO}_{3}$ and $\mathrm{HNO}_{3}-\mathrm{H}_{2} \mathrm{SO}_{4}$ have been applied to introduce oxygenated functionalities, mainly carboxylic, nitro and sulfonic groups, in the walls of the CNTs [17-19]. With respect to the second approach, the incorporation of CNTs into several polymers has been reported [8, 20-23].

In spite of the many advantages presented in the heterogeneous catalysis with the NPs-CNTs, an important challenge is the recovery of the supported catalyst from liquid reaction media to reduce the environmental impact and to increase its reuse without a loss in reactivity. To overcome these issues, in this work, first MWCNTs were oxidized using $\mathrm{HNO}_{3}$ and a $\mathrm{HNO}_{3}+\mathrm{H}_{2} \mathrm{SO}_{4}$ mixture, and subsequently, silver, and copper MNPs were incorporated into the oxidized MWCNTs using the intermatrix synthesis (IMS) technique reported by Bastos-Arrieta et al. [24]. Briefly, this technique includes two steps: (1) loading the functional groups with the MNP precursor via ion exchange, for example, a metal salt or metal complex ions, and (2) formation of MNPs by chemical reduction of the metal precursor. Additionally, due to the dramatic decrease of the redox potential on the nanometer scale for several metals, it has been possible to oxidize some superficial atoms of the MNPs by another metal such as gold or platinum by a procedure known as galvanic displacement $[10,25,26]$.
Using this procedure and controlling the amount of displaced metal, it was feasible to form bimetallic NPs (Cu-Pt and $\mathrm{Ag}-\mathrm{Pt}$ ). Once the MNPs/MWCNTs were obtained, they were loaded into a polymeric membrane (PM) containing cellulose triacetate as a polymeric support and 2-nitrophenyloctyl ether as plasticizer. MWCNTs (pristine, functionalized and loaded with MNPs) were characterized by FTIR, TGA, TEM, elemental analysis, and acid base titration as well as XPS for select samples. PMs were characterized by SEM. The catalytic activity of the loaded PMs was tested in a model reaction, namely, the reduction of 4-nitrophenol to 4-aminophenol with $\mathrm{NaBH}_{4}$ in aqueous medium.

\section{Experimental}

\subsection{Materials}

All chemicals were of the highest grade available and used as received without further purification. Raw MWCNTs were provided by SES Research (carbon purity $>95 \%$, OD 10-30 nm; length 5-15 $\mu \mathrm{m}$ ). Metal nanoparticles were synthesized using the inorganic salts $\mathrm{Pt}\left(\mathrm{NH}_{3}\right)_{4} \mathrm{Cl}_{2}$ (Sigma Aldrich, 98\%), $\mathrm{AuCl}_{3}$ (Sigma Aldrich, $>99 \%$ ), $\mathrm{CuSO}_{4} \cdot 5 \mathrm{H}_{2} \mathrm{O}$ (J.T. Baker, > 99.97\%) and $\mathrm{AgNO}_{3}$ (Baker and Adamson >99.98\%). Other reagents such as $\mathrm{NaOH}$ (Sigma Aldrich, $>97 \%), \mathrm{HNO}_{3}$ (J.T. Baker, 63\%), $\mathrm{HCl}$ (Sigma Aldrich, 37\%), $\mathrm{H}_{2} \mathrm{O}_{2}$ (J.T. Baker, $30 \%$ ) and $\mathrm{H}_{2} \mathrm{SO}_{4}$ (J.T. Baker, 96\%) were used. For the preparation of the polymeric support, cellulose triacetate (CTA, Sigma Aldrich), 2-nitrophenyloctyl ether (NPOE, Sigma Aldrich, 99\%) and dichloromethane $\left(\mathrm{CH}_{2} \mathrm{Cl}_{2}\right.$, J.T. Baker, 99\%) were employed. Dissolutions were prepared using deionized from a Milli-Q system (resistivity $18.2 \mathrm{M} \Omega \mathrm{cm}$ ).

\subsection{Functionalization of MWCNTs with $\mathrm{HNO}_{3}$ (oxidation 1)}

MWCNTs (100 mg) were weighed with precision, introduced into an Erlenmeyer flask together with $50 \mathrm{~mL}$ of concentrated $\mathrm{HNO}_{3}$ and sonicated for $2 \mathrm{~h}$. The suspension was then centrifuged at $3500 \mathrm{rpm}$ for $5 \mathrm{~min}$. The MWCNTs were separated and washed thoroughly with deionized water until a neutral pH was achieved [24]. Finally, MWCNTs were dried in a vacuum drying chamber (Binder mod VDL23) at $60^{\circ} \mathrm{C}$ for $48 \mathrm{~h}$ and characterized by FTIR, elemental analysis and acid-base titration.

\subsection{Functionalization of MWCNTs with a mixture of $\mathrm{HNO}_{3}$ and $\mathrm{H}_{2} \mathrm{SO}_{4}$ (oxidation 2)}

The procedure reported by Wang et al. [19] was used with modifications. Approximately $1.00 \mathrm{~g}$ of MWCNTs was weighed and transferred to a volumetric flask, where 
$60 \mathrm{~mL}$ of a mixture of $\mathrm{H}_{2} \mathrm{SO}_{4}$ and $\mathrm{HNO}_{3}$ in a 10:9 volume ratio was added very slowly while kept under sonication. At the end of the addition, the acidic mixture was heated at $60{ }^{\circ} \mathrm{C}$ for 90 min under constant magnetic agitation. Then, $1200 \mathrm{~mL}$ of deionized water was added to stop the reaction, and the resulting suspension was filtered using a Whatman cellulose filter paper grade 5 ( $2.5 \mu \mathrm{m}$ pore size). The solid was washed with deionized water until neutral $\mathrm{pH}$ was achieved, dried under vacuum at $60^{\circ} \mathrm{C}$ for $24 \mathrm{~h}$ and characterized by FTIR, elemental analysis and acid-base titration.

\subsection{Synthesis of MNPs in MWCNTs}

Functionalized MWCNTs ( $100 \mathrm{mg}$ ) were immersed in a solution of the respective metal salt and ultrasonicated for $2 \mathrm{~h}$. For $\mathrm{Ag}$ and $\mathrm{Cu}, 20 \mathrm{~mL}$ of $10 \mathrm{mmol} \mathrm{L}^{-1} \mathrm{AgNO}_{3}$ and $\mathrm{CuSO}_{4}$ were used, respectively, and for $\mathrm{Pt}, 10 \mathrm{~mL}$ of $5 \mathrm{mmol} \mathrm{L}^{-1}$ $\mathrm{Pt}\left(\mathrm{NH}_{3}\right)_{4} \mathrm{Cl}_{2}$ was used. Four cycles of washing/centrifugation with deionized water were performed to eliminate the excess metal salt. To reduce the metal fixed in the MWCNTs, $50 \mathrm{~mL}$ of a $0.05 \mathrm{~mol} \mathrm{~L}^{-1}$ solution of sodium borohydride was added to $100 \mathrm{mg}$ and agitated with a magnetic stirrer for $2 \mathrm{~h}$; the excess borohydride was allowed to be consumed overnight. Then, several cycles of washing/centrifugation with deionized water were carried out until a neutral $\mathrm{pH}$ was achieved. Finally, MNPs-MWCNTs were dried at $60^{\circ} \mathrm{C}$ for $48 \mathrm{~h}$ and characterized by TEM, TGA and XPS.

\subsection{Synthesis of bimetallic nanoparticles (BNPs) in MWCNTs}

MWCNTs ( $50 \mathrm{mg}$ ) loaded with Ag or Cu NPs were added to $10 \mathrm{~mL}$ of deionized water and ultrasonicated for $1 \mathrm{~h}$, after which $5 \mathrm{~mL}$ of a $5 \mathrm{mmol} \mathrm{L}^{-1}$ solution of Pt(II) was added dropwise, ultrasonicated for $2 \mathrm{~h}$, and subjected to 4 cycles of washing/centrifugation with deionized water to eliminate the excess of metal. Finally, BNPs/MWCNTs were dried at $60^{\circ} \mathrm{C}$ for $48 \mathrm{~h}$ and characterized by TEM as well as XPS for select samples.

\subsection{Preparation of membranes loaded with MNPs/ MWCNTs}

Membranes were prepared by the wet phase inversion method with $70 \pm 1 \%$ CTA as the base polymer, $28 \pm 0.5 \%$ $\mathrm{w} / \mathrm{w}$ NPOE as the plasticizer and different amounts $(1,3$ and $5 \mathrm{mg}$ ) of functionalized MWCNTs or MWCNTs loaded with MNPs (Cu, Ag, Pt, Cu-Pt or Ag-Pt). The components were dissolved in $10 \mathrm{~mL}$ of dichloromethane at room temperature until complete dissolution of CTA by magnetic stirring for approximately $2 \mathrm{~h}$. After this time-period, the mixture was placed in a Petri glass dish $(5 \mathrm{~cm}$ diameter), and the solvent was evaporated overnight. The membranes were simply peeled off the Petri dish.

\subsection{Nitrophenol reduction}

Membranes were introduced into $10 \mathrm{~mL}$ of a $0.05 \mathrm{mmol} \mathrm{L}^{-1}$ 4-nitrophenol solution, and $1 \mathrm{~mL}$ of $0.22 \mathrm{M}$ sodium borohydride was added. The sample was mechanically agitated in a shaker (Burell mod 75) throughout the entire time of the experiment. At certain time intervals, aliquots were taken. After measuring the absorbance, the samples were returned to the original solution to keep the volume constant. At the end of the experiment, the membranes were recovered from the reaction vessel, washed with deionized water, and dried. The catalytic cycles were repeated 3 times.

\subsection{Material characterization}

\subsubsection{MWCNTs}

Pristine and functionalized MWCNTs were characterized by FTIR, elemental analyses and acid-base titration. Infrared spectra of samples were obtained with a Perkin-Elmer Spectrum GX FTIR spectrometer, for which MWCNTs were mixed with $\mathrm{KBr}$ to form a pellet with a mechanic press. The spectrum was acquired in the transmission mode with 128 scans. A Perkin Elmer 2400 elemental analyzer was used to obtain the carbon/nitrogen molar ratio in MWCNT samples. The analyses were based on the Pregl-Dumas technique [27] using a furnace combustion temperature of $1100^{\circ} \mathrm{C}$ and thermal conductivity detection. Furthermore, to indirectly determine the amount of carboxylic acid groups present on the surface of the MWCNTs, the ion exchange capacity was obtained. Approximately $0.04 \mathrm{~g}$ of the MWCNTs (pristine, after oxidations 1 and 2) were introduced into $10 \mathrm{~mL}$ of deionized water, previously boiled, and sonicated for $30 \mathrm{~min}$ to eliminate the $\mathrm{CO}_{2}$ adsorbed in the MWCNTs, after which nitrogen was bubbled into the suspension for $10 \mathrm{~min}$. A $10 \mathrm{mmol} \mathrm{L}{ }^{-1} \mathrm{NaOH}$ aqueous solution ( $10 \mathrm{~mL}$, previously standardized) was added and sonicated for $2 \mathrm{~h}$. The suspension was filtered, and the filtrate was titrated with a $10 \mathrm{mmol} \mathrm{L}^{-1} \mathrm{HCl}$ solution (previously standardized). All the analyses were performed on a duplicate basis.

\subsubsection{MNPs/MWCNTs}

First, the amount of metal fixed on the functionalized MWCNTs was determined by two analytical methods, FAAS and TG. For the former, $10 \mathrm{mg}$ was introduced into $10 \mathrm{~mL}$ of concentrated nitric acid or aqua regia for samples containing Pt. The suspension was agitated and heated 
at $80{ }^{\circ} \mathrm{C}$ until dryness, and then, $2 \mathrm{~mL}$ of $\mathrm{H}_{2} \mathrm{O}_{2}$ was added for the complete oxidation of the metals. The suspension was again agitated and heated until approximately $90 \%$ of the original volume was eliminated. Deionized water was added, and the suspension was filtered in hot water. After several washings of the filter paper, the solution was made up to a volume of $25 \mathrm{~mL}$ with $2 \%(\mathrm{v} / \mathrm{v}) \mathrm{HNO}_{3}$. A Perkin Elmer 3100 FAA spectrometer was used for the determination of the metal content in the MWCNTs according to the conditions established by the manufacturer, using a standard addition method. Thermogravimetric analyses were performed on a TA Instruments Q50 instrument. Samples consisting of $10 \mathrm{mg}$ of MNPs/MWCNTs were heated from 20 to $800^{\circ} \mathrm{C}$ at a heating rate of $10^{\circ} \mathrm{C} / \mathrm{min}$ and analyzed under an air flow. The total metal content was obtained from the residue at $800^{\circ} \mathrm{C}$.

Additionally, characterization of the material was carried out using TEM and XPS. TEM images were obtained with a JEOL JEM-2010 microscope at an acceleration voltage of $200 \mathrm{kV}$. For sample preparation, approximately $1 \mathrm{mg}$ was dispersed in $5 \mathrm{~mL}$ of acetone in an ultrasonic bath for $10 \mathrm{~min}$, and one drop of the dispersion was placed on the grid and allowed to dry before TEM analysis. XPS experiments were performed with a JEOL JPS-9200 spectrometer by using monochromatic $\mathrm{Mg} \mathrm{K}_{\alpha}$ radiation with an energy of $1253.6 \mathrm{eV}$ at $200 \mathrm{~W}$. Dried samples were mounted on carbon tape over paper. Core-level binding energies were determined by using the $C 1 s$ peak at $284.8 \mathrm{eV}$ as the charge [28]. Deconvolution and literature were used to assign the peaks.

\subsubsection{MNPs/MWCNTs/PMs}

SEM images of membranes loaded with MNPs/MWCNTs were obtained on a Zeiss Merlin FE-SEM instrument at an acceleration voltage of $1.0 \mathrm{kV}$. To obtain cross-sectional images, the membranes (pristine, with MWCNTs and with MNPs/MWCNTs) were frozen with liquid nitrogen and cut, after which the samples were placed over carbon tape and introduced into the microscope.

\section{Results and discussion}

\subsection{MWCNTs}

In Fig. 1, the IR spectra of the pristine (MWCNT $)$ and oxidized (MWCNT_ox 1 and MWCNT_ox ${ }_{2}$ ) carbon nanotubes are shown. The peak at approximately $3440 \mathrm{~cm}^{-1}$ is attributed to the elongation of the $\mathrm{O}-\mathrm{H}$ present in the carboxylic groups as well as in water; at $1532 \mathrm{~cm}^{-1}$, the torsion band of the $\mathrm{O}-\mathrm{H}$ bond is observed. The signal at $1641 \mathrm{~cm}^{-1}$ corresponds to the elongation of the $\mathrm{C}=\mathrm{C}$ double bond.

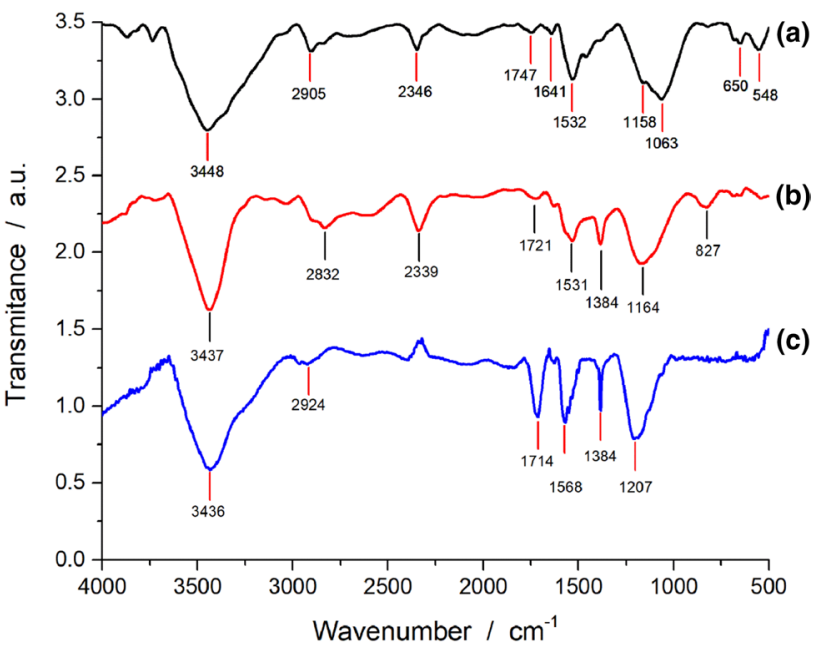

Fig. 1 IR spectra of MWCNTp (a), MWCNT_ox 1 (b), and MWCNT_ox 2 (c)

The bands that appear at approximately $2832-2905 \mathrm{~cm}^{-1}$, $1721 \mathrm{~cm}^{-1}$ and $1164 \mathrm{~cm}^{-1}$ are due to the elongation of the aliphatic $\mathrm{C}-\mathrm{H}$ groups, carboxylic $\mathrm{C}=0$ groups and $\mathrm{C}-\mathrm{O}$ groups, respectively [29-33]. The intense signal observed at approximately $2340 \mathrm{~cm}^{-1}$ is commonly related to $\mathrm{CO}_{2}$ that may be adsorbed in the material. This group of signals confirms the presence of oxygenated groups in the MWCNTs. Additionally, signals corresponding to the symmetric and asymmetric elongations of the nitro $\left(-\mathrm{NO}_{2}\right)$ groups are observed at 1384 and $1531 \mathrm{~cm}^{-1}$; respectively. However, both signals only appear together in the MWCNT_ox ${ }_{1}$ and MWCNT_ox ${ }_{2}$ spectra, thus, corroborating that the MWCNT sample does not contain nitro groups. A small signal at approximately $1747 \mathrm{~cm}^{-1}$ in the MWCNT is observed, which slightly increases its intensity for the MWCNT_ox ${ }_{1}$; while for the MWCNT_ox , the signal is much more intense. This signal corresponds to carbonyl groups, as in carboxylic acids, which can be used for the cationic ion exchange with metals and their subsequent reduction and formation of MNPs in the MWCNTs.

Elemental analyses were carried out on the same samples to determine the nitrogen content, which could originate from amines, amides and nitro groups, with the latter being the only group possible to identify in the IR spectra. For MWCNT ${ }_{p}$ MWCNT_ox ${ }_{1}$ and MWCNT_ox ${ }_{2}$ C/N molar ratios of $259.3 \pm 42.5,214.1 \pm 29.9$ and $119.2 \pm 33.7$, respectively, were found. These analyses were carried out on a quadruplicate basis. As the ratio of carbon/nitrogen diminishes, the amount of nitrogen found in the MWCNTs increases. Thus, the amount of nitrogen in the MWCNTs follows the order MWCNT_ox $>$ $>$ MWCNT_ox ${ }_{1}>$ MWCNT $_{p^{\prime}}$ and the same trend is observed in the IR spectra.

With respect to the ion exchange capacity of the three samples of MWCNTs, the results are shown in Table 1. 
Table 1 lon exchange capacity values for the $\mathrm{MWCNT}_{\mathrm{p}}$ MWCNT_ox ${ }_{1}$ and MWCNT_ox 2 samples

\begin{tabular}{ll}
\hline Nanotube & $\begin{array}{l}\text { lon exchange } \\
\text { capacity } \\
\text { (meq g }\end{array}$ \\
\hline MWCNT $_{\text {p }}$ & $0.201 \pm 0.012$ \\
MWCNT_ox $_{1}$ & $1.073 \pm 0.035$ \\
MWCNT_ox & $21.15 \pm 0.29$ \\
\hline
\end{tabular}

These values indicate that as the strength of the oxidative procedure increases, higher ion exchange capacity values are obtained. This observation correlates well with the results obtained by FTIR, where a higher content of carbonyl groups was observed in the MWCNT_ox ${ }_{2}$ sample.

The characterization of the MWCNTs by TEM indicated the morphological changes that occur as a consequence of the functionalization procedure used. It is well known that oxidation of MWCNTs not only permits their functionalization, but also aids in their purification and surface cleaning. In the images of pristine MWCNTs shown in Fig. 2a, b, deposits of graphite (regions indicated with black arrows) were observed, probably originating from the synthetic method of the MWCNTs. In Fig. 2c, d, these layers of graphite are not observed; however, the oxidative treatments degraded the outer walls of the MWCNTs (sites indicated by the red arrows). It has been reported that oxidants, such as nitric acid, react with the defects found in the MWCNTs originating the degradation of the walls or opening the (a)

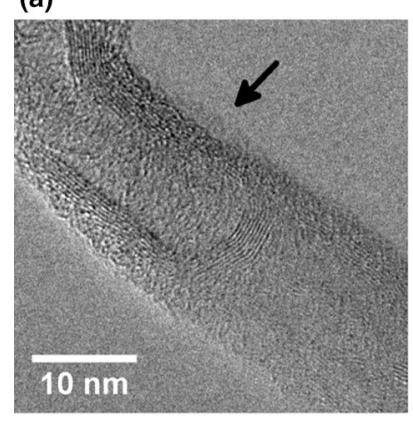

(c)

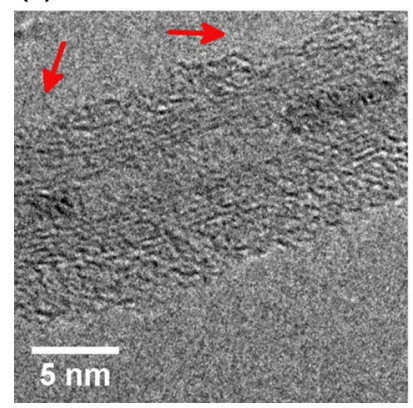

(b)

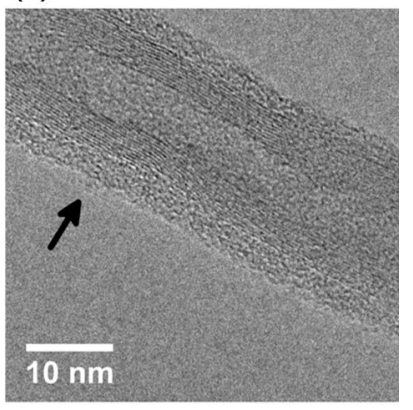

(d)

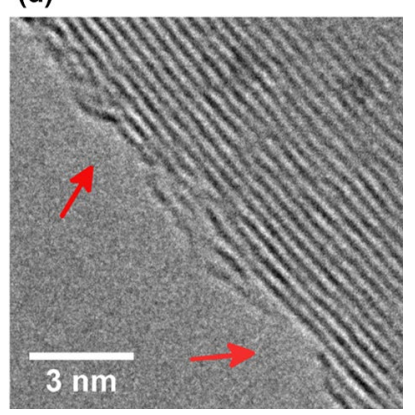

Fig. 2 TEM images for $\operatorname{MWCNT}_{\mathrm{p}}$ (a, b), MWCNT_ox ${ }_{1}$ (c), and MWCNT_ox 2 (d)

edges of fullerenes [34]. Consequently, when functionalizing the MWCNTs, a balance between increasing the functionalization and conserving the integrity of the NTs must be taken into account.

\subsection{Synthesis of bimetallic nanoparticles}

According to Plieth [26] and Aherne et al. [35], for the formation of $\mathrm{Cu}$ and $\mathrm{Ag}$ bimetallic nanoparticles in the presence of $\mathrm{Pt}$, a galvanic displacement takes place. On a nanometer scale, the reduction potentials of $\mathrm{Ag}$ and $\mathrm{Cu}$ diminish in such a way that platinum salt is capable of oxidizing these metals. At the expense of the superficial atoms, $\mathrm{Ag}$ or $\mathrm{Cu}$, it is possible to form bimetallic NPs or even to displace all of the original metal, forming only NPs of the noble metal used.

The synthesis of $\mathrm{Cu}-\mathrm{Pt}$ and $\mathrm{Ag}-\mathrm{Pt}$ bimetallic particles was realized on the previously obtained functionalized MWCNTs using the procedure described above. As an example, the galvanic displacement is represented in reaction (1) for the Pt-Ag NPs.

$$
\begin{aligned}
& 2\left[\mathrm{CNT}-\mathrm{COO}^{-}\right] \mathrm{Na}^{+} \mathrm{Ag}^{0}+\mathrm{xPt}\left(\mathrm{NH}_{3}\right)_{4}^{2+} \\
& \quad \rightarrow\left(\left[\mathrm{CNT}-\mathrm{COO}^{-}\right] \mathrm{Na}^{+}\right)_{2} \mathrm{Pt}_{\mathrm{x}}^{0}-\mathrm{Ag}_{1-2 \mathrm{x}}^{0} \\
& \quad+2 \mathrm{xAg}^{+}+4 \mathrm{xNH} \mathrm{NH}_{3}
\end{aligned}
$$

TEM images of the MWCNTs show the formation of MNPs on the surface. In Fig. 3, images for select samples

(a)

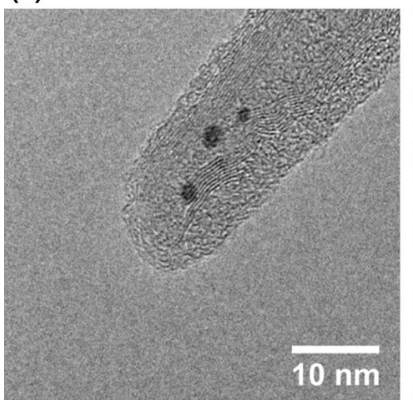

(c)

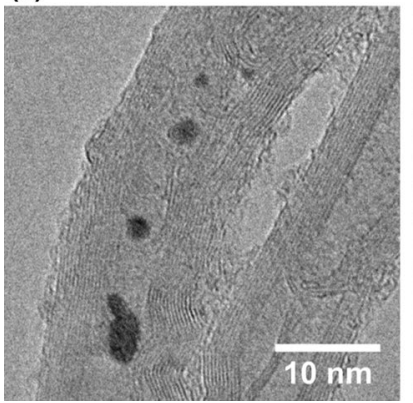

(b)

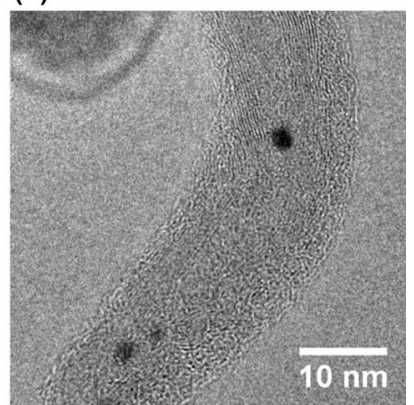

(d)

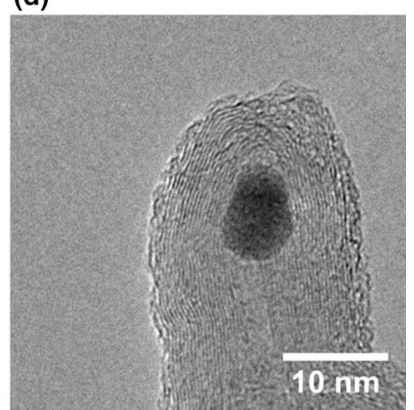

Fig. 3 HR-TEM images of AgNPs/MWCNTs_ox $(\mathbf{a}, \mathbf{b})$; Ag-Pt NPs/ MWCNTs_Ox 2 (c, d) 
are presented. It is possible to observe MWCNTs with and without MNPs on the surface (Fig. 1d) as a consequence of the mild oxidation conditions for MWCNTs compared with those used in other works [19]. The mean diameter for all the nanoparticles obtained is given in Table 2. The size of the Ag-Pt NPs is slightly larger than for the AgNPs (Fig. 4). The same trend was observed in the case of the Cu-PtNPs and CuNPs, but the difference is more significative. These results may be explained on the basis of the atomic radii of $\mathrm{Ag}$ and $\mathrm{Cu}$ and the stoichiometry of the displacement reactions by platinum. However, it has been reported that galvanic displacement tends to produce hollow, porous, or multicrystalline structures when a Pt(II) salt is used as a metallic precursor [36-39]. To clarify these observations further studies must be carried out. It is also important to note the difference between the MNPs obtained by the intermatrix synthesis and the MNPs inherently present in the MWCNTs due to the traces of the metal catalyst used in their fabrication, which usually appear inside the NTs (Fig. 2c).

Table 3 shows the results of the metal contents determined in the selected samples of MWCNTs containing NPs and BNPs by TGA and FAAS after acid digestion. Similar results were obtained with both techniques which corroborate the accuracy of these values. As can be seen the metal content in the samples prepared by the oxidation 2 procedure is always higher than the corresponding samples obtained by oxidation 1 .

In the XPS spectrum of the Ag-Pt NPs/MWCNTs_ox sample (Fig. 5), only the signal corresponding to $\mathrm{Pt}^{0}$ is observed; the maximum of the $4 f_{7 / 2}$ band is localized at $71.4 \mathrm{eV}$. Deconvolution of the signal was performed assuming a $3.3 \mathrm{eV}$ separation, which is characteristic for $\mathrm{Pt}$, and an area ratio of 3:4 between the $4 f_{5 / 2}$ and $4 f_{7 / 2}$ levels. The positive displacement in the binding energy is due to a decrease of the electronic density of the Pt atoms because of their interaction with a more electronegative species. Wisniewska and Ziolek described the interaction between Pt and Ag in metal alloys of these elements and reported a displacement of the spectral band of the $4 f_{7 / 2}$

Table 2 Mean particle size for MNPs/MWCNTs catalyst

\begin{tabular}{lc}
\hline Sample & Size $(\mathrm{nm})$ \\
\hline AgNPs/MWCNTs_ox ${ }_{1}$ & $2.2 \pm 1.3$ \\
Ag-Pt NPs/MWCNTs_ox $_{1}$ & $2.9 \pm 1.5$ \\
CuNPs/MWCNTs_ox ${ }_{1}$ & $2.9 \pm 1.1$ \\
Cu-Pt NPs/MWCNTs_ox ${ }_{1}$ & $5.2 \pm 2.9$ \\
AgNPs/MWCNTs_ox & $2.3 \pm 1.1$ \\
Ag-Pt NPs/MWCNTs_ox & $2.7 \pm 1.2$ \\
CuNPs/MWCNTs_ox & $2.1 \pm 1.2$ \\
Cu-Pt NPs/MWCNTs_ox & $3.3 \pm 2.2$ \\
\hline
\end{tabular}

level to $71.6 \mathrm{eV}$ [40], which is very close to the experimental value obtained for the Ag-Pt NPs/MWCNTs_ox ${ }_{2}$ sample. Thus, it is concluded that the signal is due to $\mathrm{Pt}^{0}-\mathrm{Ag}^{0}$ alloy, indicating the displacement of $\mathrm{Ag}$ atoms by $\mathrm{Pt}$ and the formation of the bimetallic NPs in the MWCNTs.

\subsection{MNPs/MWCNTs/PMs}

The amounts used for the preparation of the polymeric membranes with CTA are given in the experimental section. Although three different amounts of MNPs/MWCNTs were used to study the effect of concentration on the loading into the CTA polymer, the best results were obtained for the $5 \mathrm{mg}$ catalyst loading.

To indicate the morphological changes of MNPs/ MWCNTs/PMs, both the flat face and cross-section of the membranes were analyzed by SEM. The blank membranes present a smooth and defect-free structure in the crosssection and the flat face on the Petri dish side. However, microvoids appear in the cavities and are probably formed as consequence of the method used to prepare the membranes, wet phase inversion, since the formation of bubbles during the solvent evaporation is possible. After the incorporation of the MWCNTs into the membrane, the cross-section and the air contact face exhibit a highly porous structure with a very thin compact porous matrix, with a mean pore size of $208 \pm 73 \mathrm{~nm}$ in the cross section, as measured by SEM. The same morphology was observed for all membranes with MNPs/MWCNTs. Figure 6 shows comparative images of several membranes. In heterogeneous catalysis, porosity is important to facilitate the access of the reactants to the MNP surface. Furthermore, these observations agree with previous studies, where it has been reported that the incorporation of AgNPs promoted an increase of the porosity and roughness of the materials obtained by ion exchange [41].

\subsection{Application: catalytic activity in the reduction of 4-nitrophenol}

The catalytic activities of the obtained materials were determined using the reduction of 4-nitrophenol to 4-aminophenol with an aqueous $\mathrm{NaBH}_{4}$ solution as a model reaction. This reaction serves as an almost ideal model to test the catalytic activity of the materials since it does not take place in the absence of a catalyst. It is well-known that under conditions of an excess of $\mathrm{NaBH}_{4}$, to maintain its concentration practically constant throughout the experiment, the reaction follows pseudo-first order kinetics. The most frequently used catalysts are based on gold or platinum $[2,8,42-46]$. 

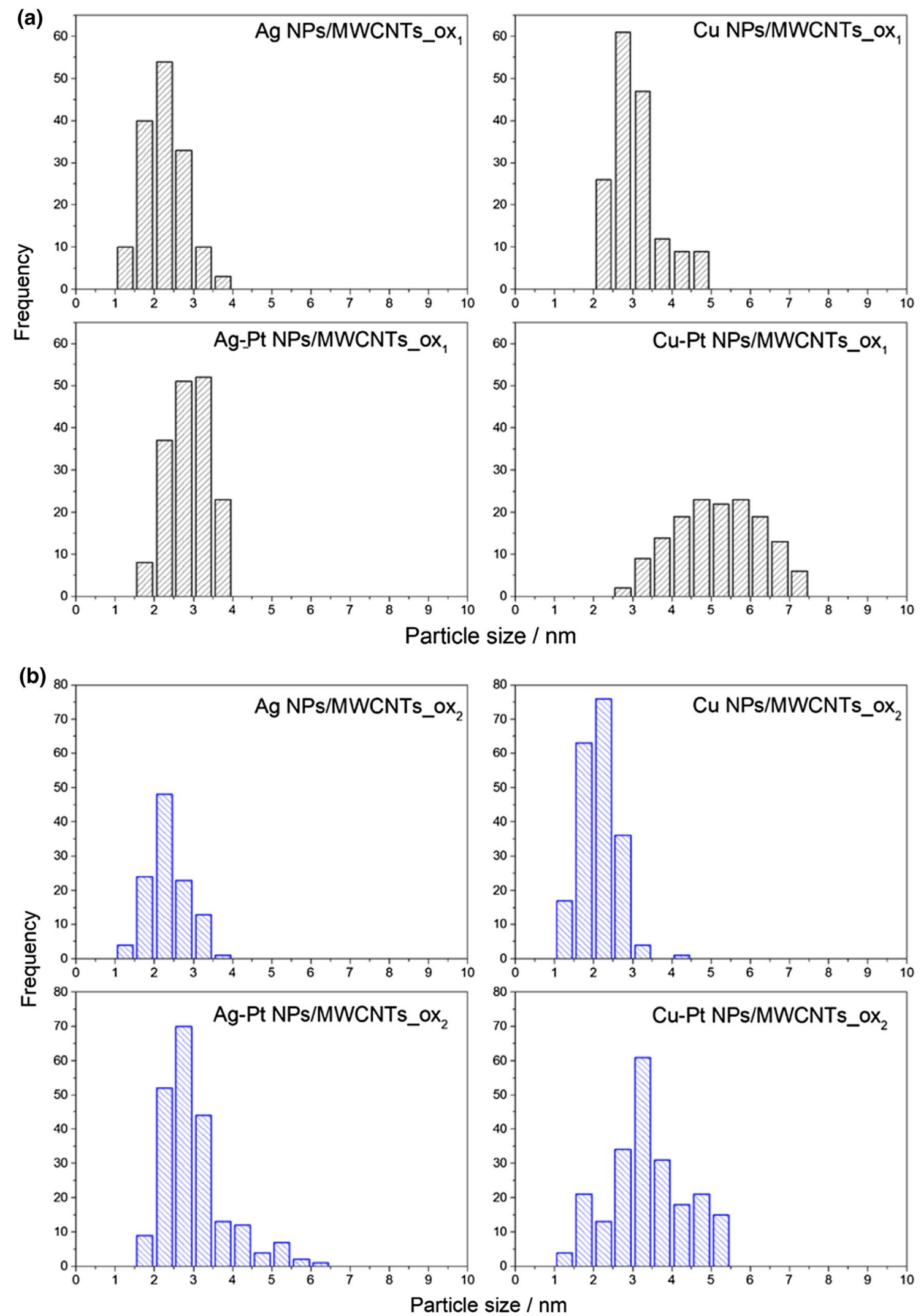

Fig. 4 Particle size distribution for MNPs/MWCNTs with a oxidation 1, and $\mathbf{b}$ oxidation 2 
Table 3 Metal contents in mono and bimetallic NPs/MWCNTs. Results are expressed in $\mathrm{mg}$ of metal/g of material obtained

\begin{tabular}{|c|c|c|c|c|c|c|}
\hline \multirow[t]{2}{*}{ Sample } & \multicolumn{3}{|l|}{ TGA } & \multicolumn{3}{|l|}{ FAAS } \\
\hline & $\mathrm{C}_{\mathrm{Ag}}\left(\mathrm{mg} \mathrm{g}^{-1}\right)$ & $\mathrm{C}_{\mathrm{Cu}}\left(\mathrm{mg} \mathrm{g}^{-1}\right)$ & $C_{P t}\left(\mathrm{mg} \mathrm{g}^{-1}\right)$ & $\mathrm{C}_{\mathrm{Ag}}\left(\mathrm{mg} \mathrm{g}^{-1}\right)$ & $\mathrm{C}_{\mathrm{Cu}}\left(\mathrm{mg} \mathrm{g}^{-1}\right)$ & $C_{P t}\left(\mathrm{mg} \mathrm{g}^{-1}\right)$ \\
\hline AgNPs/MWCNTs_ox 1 & 12.1 & N.D. & N.D. & 10.6 & N.D. & N.D. \\
\hline Ag-Pt NPs/MWCNTs_ox 1 & 5.2 & N.D. & 6.4 & 6.7 & N.D. & 7.9 \\
\hline CuNPs/MWCNTs_ox & N.D. & 10.2 & N.D. & N.D. & 9.4 & N.D. \\
\hline Cu-Pt NPs/MWCNTs_ox 1 & N.D. & 7.3 & 5.0 & N.D. & 6.8 & 4.1 \\
\hline AgNPs/MWCNTs_ox 2 & 40.8 & N.D. & N.D. & 37.9 & N.D. & N.D. \\
\hline Ag-Pt NPs/MWCNTs_ox 2 & 27.3 & N.D. & 21.1 & 26.6 & N.D. & 22.2 \\
\hline CuNPs/MWCNTs_ox ${ }_{2}$ & N.D. & 10.3 & N.D. & N.D. & 9.3 & N.D. \\
\hline $\mathrm{Cu}-\mathrm{Pt}$ NPs/MWCNTs_ox 2 & N.D. & 13.7 & 7.5 & N.D. & 16.5 & 9.9 \\
\hline
\end{tabular}

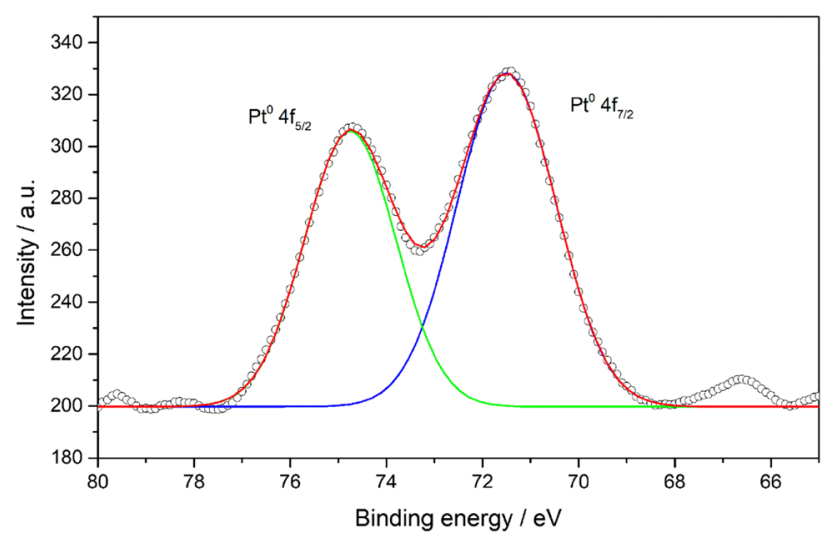

Fig. 5 Photoelectronic spectrum of the Pt region for the $\mathrm{Ag}-\mathrm{Pt}$ NPs/MWCNTs_ox 2 sample showing the signals of the Pt-Ag interaction at 71.4 and $74.7 \mathrm{eV}$ for the $4 f_{7 / 2}$ and $4 f_{5 / 2}$ levels, respectively. The circles represent the experimental data, and the continuous lines represent the adjustment to the theoretical model

It was observed that neither the blank membrane nor the membrane containing the MWCNTs catalyze the reduction of 4-nitrophenol. Thus, it can be concluded that the catalytic activity is due to the presence of the MNPs.

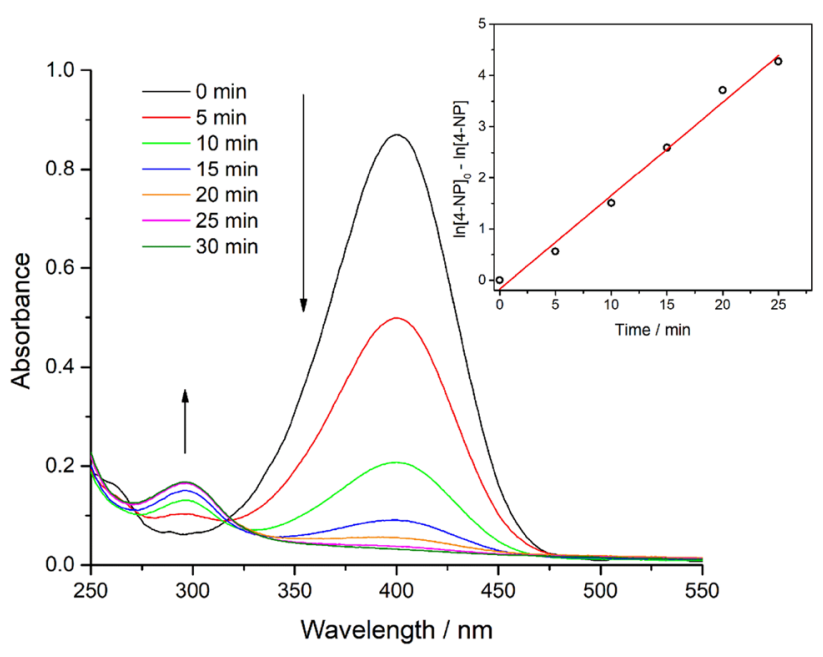

Fig. 7 Catalytic reduction of $10 \mathrm{~mL}$ of $5 \mathrm{mmol} \mathrm{L}^{-1}$ 4-nitrophenol with $0.02 \mathrm{~mol} \mathrm{~L}^{-1} \mathrm{NaBH}_{4}$ using $5 \mathrm{mg}$ of Ag-Pt NPs/MWCNTs_ox 2

The catalytic tests were carried out as indicated in the experimental section. The progress of the reaction was monitored by UV-Vis spectroscopy. The aqueous solution of 4-nitrophenol presents a light-yellow color in (a)

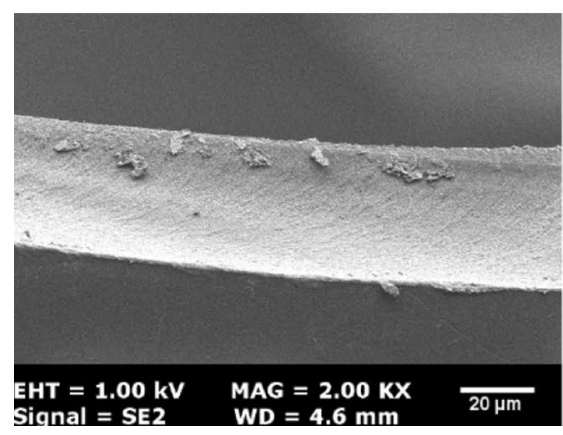

(b)

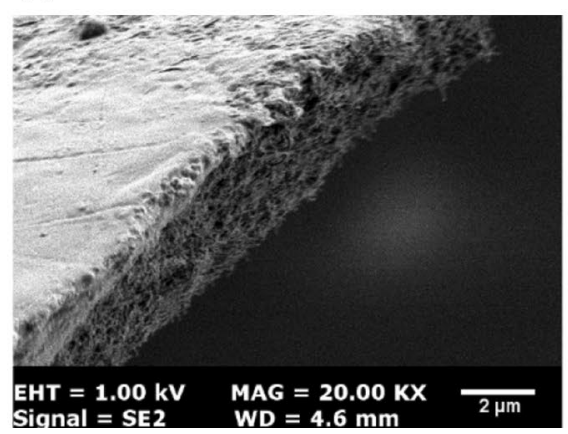

(c)

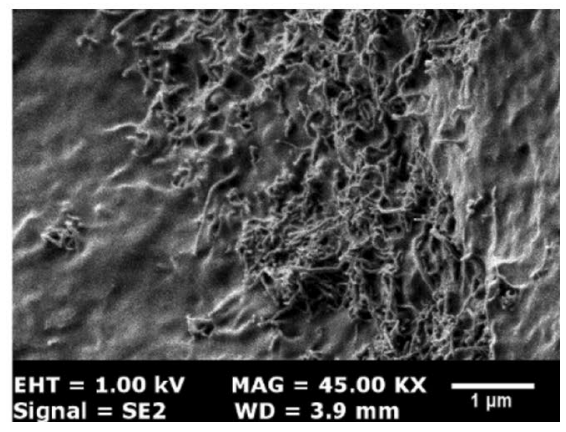

Fig. 6 SEM images of the $\mathbf{a}$ cross section of blank membrane; $\mathbf{b}$ cross section of the membrane loaded with MWCNTs; $\mathbf{c}$ air contact face of $\mathrm{Ag}-\mathrm{Pt} / \mathrm{MWCNTs} / \mathrm{PM}$

\section{SN Applied Sciences}


Table 4 Apparent rate constants normalized by the amount of metal for the MNPs/MWCNTs/PMs and MNPs/MWCNTs catalysts in the polymeric membranes

\begin{tabular}{|c|c|}
\hline MNPs/MWCNTs/PMs & $\begin{array}{l}\text { Normalized rate constant } \\
\left(\mathrm{s}^{-1} \mathrm{~mol}^{-1}\right)\end{array}$ \\
\hline AgNPs/MWCNTs_ox 1 & $228.2 \pm 5.4$ \\
\hline Ag-Pt NPs/MWCNTs_ox & $1232.5 \pm 16.6$ \\
\hline CuNPs/MWCNTs_ox & $113.4 \pm 18.7$ \\
\hline Cu-Pt NPs/MWCNTs_ox & $939.3 \pm 8.4$ \\
\hline AgNPs/MWCNTs_ox 2 & $617.2 \pm 12.3$ \\
\hline Ag-Pt NPs/MWCNTs_ox ${ }_{2}$ & $1706.7 \pm 21.4$ \\
\hline CuNPs/MWCNTs_ox ${ }_{2}$ & $342.1 \pm 4.8$ \\
\hline $\mathrm{Cu}-\mathrm{Pt}$ NPs/MWCNTs_ox ${ }_{2}$ & $1148.4 \pm 25.8$ \\
\hline MNPs/MWCNTs & $\begin{array}{l}\text { Normalized rate constant } \\
\left(\mathrm{s}^{-1} \mathrm{~mol}^{-1}\right)\end{array}$ \\
\hline Ag-Pt NPs/MWCNTs_ox ${ }_{2}$ & $6021.8 \pm 25.8$ \\
\hline Cu-Pt NPs/MWCNTs_ox ${ }_{2}$ & $3734.5 \pm 19.8$ \\
\hline
\end{tabular}

acidic media ( $\mathrm{pKa}=7.15$ ) [47]. At higher $\mathrm{pH}$ values, the 4-nitrophenolate ion exhibits a strong yellow color with an absorption band at $400 \mathrm{~nm}$, while 4-aminophenol is colorless and presents an absorption band at $305 \mathrm{~nm}$ [44].

In Fig. 7, the results of the catalytic evaluation of the Ag-Pt NPs/MWCNTs_ox 2 system are shown. The catalytic activity of the MNPs/MWCNTs was only approximately 3 times higher than for the MNPs/MWCNTs/PMs catalysts (Table 4) indicating that it is not substantially affected after the inclusion into the membrane. Overall results indicate that the catalytic activity of the studied systems depends mainly on the MNPs size and the metal content. While the size of the NPs is determined by the intermatrix synthesis
Table 5 Comparative literature data of the rate constants for the reduction of 4-nitrophenol

\begin{tabular}{|c|c|c|}
\hline Catalyst system & Rate constant $\left(\mathrm{s}^{-1}\right)$ & References \\
\hline PdNPs/SPES-C & 0.0132 & {$[42]$} \\
\hline CNFs/AgNPs & 0.0062 & {$[48]$} \\
\hline Au@PZS@CNTs & 0.0018 & [8] \\
\hline AgNPs/MWCNTs@S.L & 0.0192 & [49] \\
\hline CMC-PVA hydrogel/Au@MWCNTs & 0.0049 & {$[50]$} \\
\hline $\mathrm{Cu}_{2} \mathrm{O}-\mathrm{MWCNTS}$ & 0.0096 & {$[51]$} \\
\hline $\mathrm{Ag}-\mathrm{Pt}$ NPs/MWCNTs_ox $2 / \mathrm{PM}$ & $0.0031 \pm 0.0001$ & This work \\
\hline Ag-Pt NPs/MWCNTs_ox ${ }_{2}$ & $0.0108 \pm 0.0001$ & This work \\
\hline
\end{tabular}

SPES-C sulphonated polyethersulphone with Cardo group, CNF carbon nanofibers, $P Z S$ poly(cyclotriphosphazene-Co-4,40-sulfonyldiphenol), S. L., Stachys lavandulifolia extract, CMC-PVA carboxymethyl cellulose-polyvinyl alcohol

technique, the metal content is mainly controlled by the functionalization procedure of MWCNTs.

When several cycles were performed, in most cases, a decrease in the reaction rate was observed as the number of cycles increased (Fig. 8). After $2 \mathrm{~h}$ of reaction, the percentage of conversion decreases from 95 to $80 \%$ from the first to the third cycle in the case of the Ag-Pt NPs/MWCNTs_ox $2 / P M$ and from 91 to $44 \%$ for the $\mathrm{Cu}-\mathrm{Pt}$ NPs/MWCNTs_ox 2 /PM. The recovery procedure for the NPs/MWCNTs/PMs is not only faster and easier but also no traces of the metals were found in the reaction media, as indicated by the results obtained after acid digestion and ICP-OES determination. Consequently, this decrease may be due to the adsorption of chemical species present in the reaction medium on the catalyst
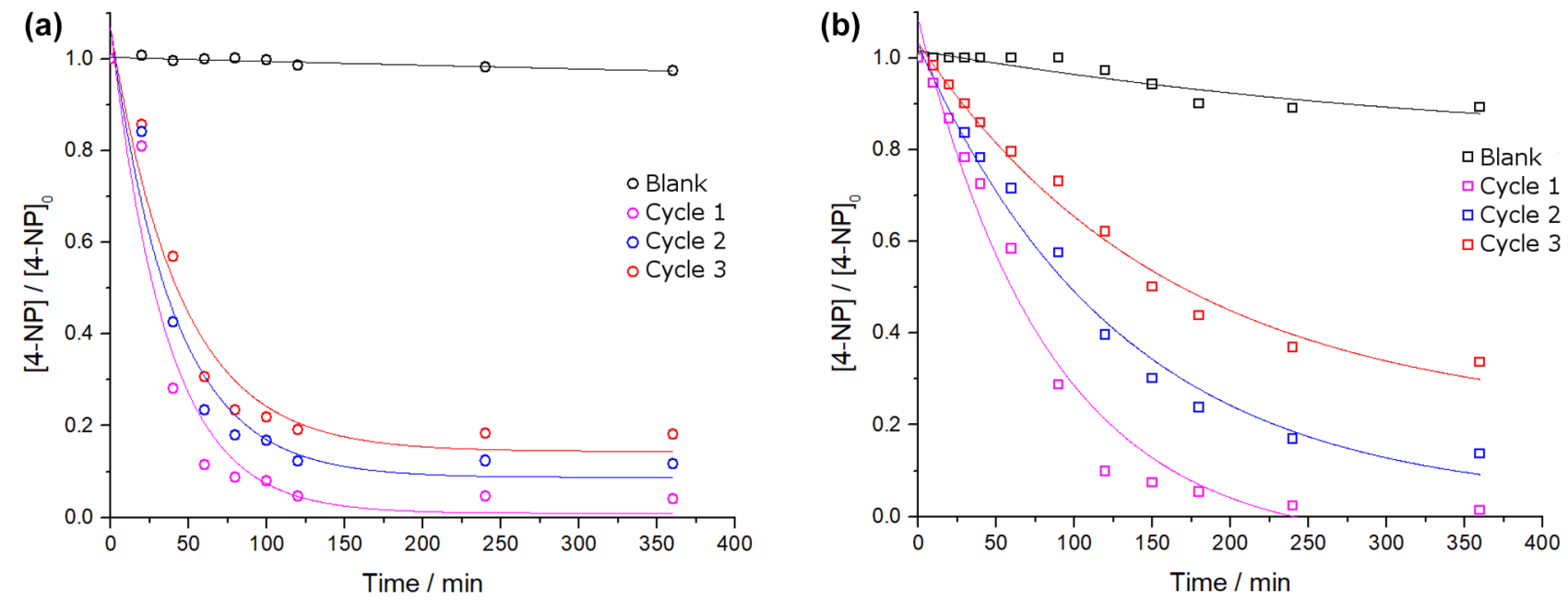

Fig. 8 Catalytic cycles for the reduction of 4-nitrophenol using PMs loaded with a Ag-Pt NPs/MWCNTs_ox , and b Cu-Pt NPs/MWCNTs_ox 2 as catalysts 
surface. The catalysts prepared in this study show promising results when compared with the reported catalysts in the literature as presented in Table 5.

\section{Conclusions}

In summary, the synthesis of MNPs and BNPs supported on functionalized MWCNTs and their incorporation into a polymeric membrane was successfully achieved through a simple, efficient and reproducible procedure. Well-controlled small size NPs were obtained, as shown by TEM characterization, using the intermatrix synthesis technique no matter the procedure used for the functionalization of the MWCNTs. Nevertheless, TGA and FAAS results proved that the oxidation procedure with a mixture of nitric-sulfuric acids allows to load more metallic phase in the MWCNTs. The highest rate constant was obtained for the bimetallic system Ag-Pt NPs/MWCNT_ox 2 . XPS characterization of this catalyst proved the interaction between both metals and the coating of $\mathrm{Ag}$ by Pt, which may explain the high stability of the BNPs. Likewise, the catalysts when loaded into a polymeric membrane proved to have comparable catalytic performance as other supported catalysts previously reported. Nevertheless, they present the important advantages of easy recovery and reuse. These catalysts could be used for environmental applications such as the reduction of nitroaromatic compounds and water treatment.

Acknowledgements This work was supported by DGAPA-UNAM (Project IN1 16017). V. Esquivel (Exp. Num. 292787), gratefully thanks CONACyT for doctoral and "Beca Mixta" scholarships. Gratitude is also expressed to the technical services of the Universidad Nacional Autónoma de México (R. Iván Puente Lee, Víctor H. Lemus Neri, USAIFQ, UNAM), Servei de Microscopia Universitat Autònoma de Barcelona, Dr. Gustavo Lopez Tellez (CCIQS-UAEMex) for the XPS analysis and Dra. Guillermina Burillo and Alejandra Ortega (IIN-UNAM) for thermal analysis.

\section{Compliance with ethical standards}

Conflict of interest The authors declare that they have no conflict of interest.

\section{References}

1. Serp P, Corrias M, Kalck P (2003) Carbon nanotubes and nanofibers in catalysis. Appl Catal A Gen 253(2):337-358

2. Liu YK, Jiang GH, Li L, Chen H, Huang Q, Jiang TT, Du XX, Chen WX (2015) Preparation of Au/PAN nanofibrous membranes for catalytic reduction of 4-nitrophenol. J Mater Sci 50(24):8120-8127

3. Antolini E (2009) Carbon supports for low-temperature fuel cell catalysts. Appl Catal B Environ 88(1-2):1-24
4. Park KW, Sung YE, Han S, Yun Y, Hyeon T (2004) Origin of the enhanced catalytic activity of carbon nanocoil-supported PtRu alloy electrocatalysts. J Phys Chem B 108(3):939-944

5. Guo JS, Sun GQ, Wang Q, Wang GX, Zhou ZH, Tang SH, Jiang LH, Zhou B, Xin Q (2006) Carbon nanofibers supported $\mathrm{Pt}-\mathrm{Ru}$ electrocatalysts for direct methanol fuel cells. Carbon 44(1):152-157

6. Hsu NY, Chien CC, Jeng KT (2008) Characterization and enhancement of carbon nanotube-supported PtRu electrocatalyst for direct methanol fuel cell applications. Appl Catal B Environ 84(1-2):196-203

7. Prabhuram J, Zhao TS, Liang ZX, Chen R (2007) A simple method for the synthesis of PtRu nanoparticles on the multi-walled carbon nanotube for the anode of a DMFC. Electrochim Acta 52(7):2649-2656

8. Wang XZ, Fu JW, Wang MH, Wang YJ, Chen ZM, Zhang JA, Chen JF, Xu Q (2014) Facile synthesis of Au nanoparticles supported on polyphosphazene functionalized carbon nanotubes for catalytic reduction of 4-nitrophenol. J Mater Sci 49(14):5056-5065

9. Notar Francesco I, Fontaine-Vive F, Antoniotti S (2014) Synergy in the catalytic activity of bimetallic nanoparticles and new synthetic methods for the preparation of fine chemicals. ChemCatChem 6(10):2784-2791

10. Papadimitriou $S$, Armyanov S, Valova E, Hubin A, Steenhaut O, Pavlidou E, Kokkinidis G, Sotiropoulos S (2010) Methanol oxidation at $\mathrm{Pt}-\mathrm{Cu}, \mathrm{Pt}-\mathrm{Ni}$, and $\mathrm{Pt}-\mathrm{Co}$ electrode coatings prepared by a galvanic replacement process. J Phys Chem C 114(11):5217-5223

11. Toshima N, Yonezawa T (1998) Bimetallic nanoparticles-novel materials for chemical and physical applications. New J Chem 22(11):1179-1201

12. Wang D, Li Y (2011) Bimetallic nanocrystals: liquid-phase synthesis and catalytic applications. Adv Mater 23(9):1044-1060

13. Zhong CJ, Maye MM (2001) Core-shell assembled nanoparticles as catalysts. Adv Mater 13(19):1507-1511

14. Hull RV, Li L, Xing YC, Chusuei CC (2006) Pt nanoparticle binding on functionalized multiwalled carbon nanotubes. Chem Mater 18(7):1780-1788

15. Kharisov BI, Kharissova OV, Ortiz Méndez U, De La Fuente IG (2016) Decoration of carbon nanotubes with metal nanoparticles: recent trends. Synth React Inorg Met 46(1):55-76

16. Yoshii K, Tsuda T, Arimura T, Imanishi A, Torimoto T, Kuwabata $S$ (2012) Platinum nanoparticle immobilization onto carbon nanotubes using Pt-sputtered room-temperature ionic liquid. RSC Adv 2(22):8262-8264

17. Giordano R, Serp P, Kalck P, Kihn Y, Schreiber J, Marhic C, Duvail $J \mathrm{~L}$ (2003) Preparation of rhodium catalysts supported on carbon nanotubes by a surface mediated organometallic reaction. Eur J Inorg Chem 2003(4):610-617

18. Lordi V, Yao N, Wei J (2001) Method for supporting platinum on single-walled carbon nanotubes for a selective hydrogenation catalyst. Chem Mater 13(3):733-737

19. Wang L, Feng SA, Zhao JH, Zheng JF, Wang ZJ, Li L, Zhu ZP (2010) A facile method to modify carbon nanotubes with nitro/amino groups. Appl Surf Sci 256(20):6060-6064

20. El Badawi N, Ramadan AR, Esawi AMK, El-Morsi M (2014) Novel carbon nanotube-cellulose acetate nanocomposite membranes for water filtration applications. Desalination 344:79-85

21. Pal G, Kumar S (2016) Modeling of carbon nanotubes and carbon nanotube-polymer composites. Prog Aerosp Sci 80:33-58

22. Song XJ, Wang L, Mao LL, Wang ZN (2016) Nanocomposite membrane with different carbon nanotubes location for nanofiltration and forward osmosis applications. ACS Sustain Chem Eng 4(6):2990-2997 
23. Spitalsky Z, Tasis D, Papagelis K, Galiotis C (2010) Carbon nanotube-polymer composites: chemistry, processing, mechanical and electrical properties. Prog Polym Sci 35(3):357-401

24. Bastos-Arrieta J, Munoz J, Stenbock-Fermor A, Munoz M, Muraviev DN, Cespedes F, Tsarkova LA, Baeza M (2016) Intermatrix synthesis as a rapid, inexpensive and reproducible methodology for the in situ functionalization of nanostructured surfaces with quantum dots. Appl Surf Sci 368:417-426

25. Morita S, Kudo E, Shirasaka R, Yonekawa M, Nagai K, Ota $H$, N-Gamo M, Shiroishi H (2016) Electrochemical oxidation of ammonia by multi-wall-carbon-nanotube-supported Pt shell-Ir core nanoparticles synthesized by an improved Cu short circuit deposition method. J Electroanal Chem 762:29-36

26. Plieth WJ (1982) Electrochemical properties of small clusters of metal atoms and their role in the surface enhanced Raman scattering. J Phys Chem 86(16):3166-3170

27. Braun El, Pantano P (2014) The importance of an extensive elemental analysis of single-walled carbon nanotube soot. Carbon 77:912-919

28. Wang XX, Tan ZH, Zeng M, Wang JN (2014) Carbon nanocages: a new support material for Pt catalyst with remarkably high durability. Sci Rep 4(4437):1-11

29. Branca C, Frusteri F, Magazù V, Mangione A (2004) Characterization of carbon nanotubes by TEM and infrared spectroscopy. J Phys Chem B 108(11):3469-3473

30. Kim UJ, Furtado CA, Liu X, Chen G, Eklund PC (2005) Raman and IR spectroscopy of chemically processed single-walled carbon nanotubes. J Am Chem Soc 127(44):15437-15445

31. Lefrant S, Baibarac M, Baltog I (2009) Raman and FTIR spectroscopy as valuable tools for the characterization of polymer and carbon nanotube based composites. J Mater Chem 19(32):5690-5704

32. Mawhinney DB, Naumenko V, Kuznetsova A, Yates JT, Liu J, Smalley RE (2000) Infrared spectral evidence for the etching of carbon nanotubes: ozone oxidation at 298 K. J Am Chem Soc 122(10):2383-2384

33. Sbai K, Rahmani A, Chadli $H$, Bantignies JL, Hermet $P$, Sauvajol $J L$ (2006) Infrared spectroscopy of single-walled carbon nanotubes. J Phys Chem B 110(25):12388-12393

34. Santangelo $S$, Messina G, Faggio G, Abdul Rahim SH, Milone $C$ (2012) Effect of sulphuric-nitric acid mixture composition on surface chemistry and structural evolution of liquid-phase oxidised carbon nanotubes. J Raman Spectrosc 43(10):1432-1442

35. Aherne D, Gara M, Kelly JM, Gun'ko YK (2010) From Ag nanoprisms to triangular AuAg nanoboxes. Adv Funct Mater 20(8):1329-1338

36. Alia SM, Yan YS, Pivovar BS (2014) Galvanic displacement as a route to highly active and durable extended surface electrocatalysts. Catal Sci Technol 4(10):3589-3600

37. Eid K, Wang H, Wang L (2017) Chapter 6-nanoarchitectonic metals. In: Ariga K, Aono M (eds) Supra-materials nanoarchitectonics. William Andrew Publishing, Norwich, pp 135-171
38. Pasricha R, Bala T, Biradar AV, Umbarkar S, Sastry M (2009) Synthesis of catalytically active porous platinum nanoparticles by transmetallation reaction and proposition of the mechanism. Small 5(12):1467-1473

39. Sun YG, Mayers BT, Xia YN (2002) Template-engaged replacement reaction: a one-step approach to the large-scale synthesis of metal nanostructures with hollow interiors. Nano Lett 2(5):481-485

40. Wisniewska J, Ziolek M (2017) Formation of Pt-Ag alloy on different silicas - surface properties and catalytic activity in oxidation of methanol. RSC Adv 7(16):9534-9544

41. Bastos Arrieta J (2014) Bifunctional nanocomposites: surface modification of reactive matrices with functional metal nanoparticles by Intermatrix Synthesis Technique. Ph.D. Dissertation, Universitat Autònoma de Barcelona, Barcelona, Spain

42. Domènech $B$, Muñoz M, Muraviev DN, Macanás J (2012) Catalytic membranes with palladium nanoparticles: from tailored polymer to catalytic applications. Catal Today 193(1):158-164

43. Dotzauer DM, Bhattacharjee S, Wen Y, Bruening ML (2009) Nanoparticle-containing membranes for the catalytic reduction of nitroaromatic compounds. Langmuir 25:1865-1871

44. Dotzauer DM, Dai J, Sun L, Bruening ML (2006) Catalytic membranes prepared using layer-by-layer adsorption of polyelectrolyte/metal nanoparticle films in porous supports. Nano Lett 6:2268-2272

45. Liang M, Su RX, Qi W, Yu YJ, Wang LB (2014) Synthesis of welldispersed Ag nanoparticles on eggshell membrane for catalytic reduction of 4-nitrophenol. J Mater Sci 49(4):1639-1647

46. Wang HT, Dong ZX, Na CZ (2013) Hierarchical carbon nanotube membrane-supported gold nanoparticles for rapid catalytic reduction of p-nitrophenol. ACS Sustain Chem Eng 1(7):746-752

47. Haynes WM (2012) CRC handbook of chemistry and physics, 93rd edn. Taylor and Francis, Boca Raton

48. Zhang $P$, Shao $C L$, Zhang ZY, Zhang MY, Mu JB, Guo ZC, Liu YC (2011) In situ assembly of well-dispersed Ag nanoparticles (AgNPs) on electrospun carbon nanofibers (CNFs) for catalytic reduction of 4-nitrophenol. Nanoscale 3(8):3357-3363

49. Veisi H, Kazemi S, Mohammadi P, Safarimehr P, Hemmati S (2019) Catalytic reduction of 4-nitrophenol over $\mathrm{Ag}$ nanoparticles immobilized on Stachys lavandulifolia extract-modified multi walled carbon nanotubes. Polyhedron 157:232-240

50. Al-Kahtani AA, Almuqati T, Alhokbany N, Ahamad T, Naushad $M$, Alshehri SM (2018) A clean approach for the reduction of hazardous 4-nitrophenol using gold nanoparticles decorated multiwalled carbon nanotubes. J Clean Prod 191:429-435

51. Liu CH, Wang F, Liang Q, Liu J, Chen ZD, Wang SD (2016) A novel one-step synthesis method for cuprous nanoparticles on multiwalled carbon nanotubes with high catalytic activity. Ceram Int 42(15):17916-17919

Publisher's Note Springer Nature remains neutral with regard to jurisdictional claims in published maps and institutional affiliations. 